\title{
Mastering Foreign Language Competence of Ecology and Environment Managers for Mining Industry of Kuzbass
}

\author{
Oksana Greenwald ${ }^{1, *}$, Roman Islamov ${ }^{1}$, and Tatyana Sergeychick $^{1}$ \\ ${ }^{1}$ Kemerovo State University, Institute of Philology, Foreign Languages and Mediacommunications, \\ Department of Foreign Languages, 650000, 6 Krasnaya st., Kemerovo, Russia
}

\begin{abstract}
The necessity to solve nature conservation problems of Kuzbass mining industry demands from postgraduate education institutions to train highly qualified specialists in ecology and environment management. As 21 st century education is competence-based one, the article clarifies the concept of competence in education, focuses on key competences, namely foreign language competence and its relevance for specialists in ecology and environment management. Foreign language competence is acquired through the course of "Foreign Language" discipline which covers the following aspects: academic reading, academic writing and public speaking. The article also describes the experience of organizing students' individual work taking into account their motivation and specific conditions of the discipline as well. Thus, both the content of the discipline and the approach to organize students' learning contribute to mastering foreign language competence of ecology and environment managers as inherent condition of their professional efficiency for solving ecological problems of mining industry in Kuzbass region.
\end{abstract}

\section{Introduction}

Highly qualified specialists in ecology and environment management are vitally urgent for coal-mining enterprises of Kuzbass. They are to solve the following problems of the mining industry:

- assessment of design and production activity of coal-mining enterprises of Kuzbass (in the view of their impact on environment);

- ecological monitoring of regional fauna and flora (biota);

- environment management and expert activity of coal-mining enterprises;

- rational environment management and nature conservation;

- $\quad$ scientific research of regional industrial environmental issues.

Consequently, training qualified specialists in ecology and environment management for a coal-mining region is an important task of the regional higher education system. Modern postgraduate education is competence-based one; it aims at formation and

*Corresponding author: greenwald.ru@,rambler.ru 
mastering a number of competences of a future specialist, foreign language competence is among them.

\section{Analysis}

First the term competence appeared in scientific and psychological literature in the works of German scientist Jürgen Habermas [1], who used this term in the context of the theory of speech communication. In 1959 Robert White introduced the term competence into the theory of management to describe the features of individuality which are most closely connected with effective implementation of work and high motivation [2].

More attention to competence in management and strategy of supervision, the researches of scientists aimed at determination of personal qualities promoting effective functioning in professional area, and requirements of employers became a prerequisite of emergence and development of competence-based approach in education. It is commonly thought that competence-based approach in education appeared in the USA due to the publication of an article by David McClelland "Testing for competence rather than for intelligence" in 1973 [3].

Today professional education in the majority of developed countries, in spite of their cultural and national variety and specifics of economic development, unite the description of qualifications in terms of professional competences.

In English, the word competence is used along with the word competency. According to defining dictionaries they may be considered as synonyms. For example, in Collins Cobuild Advanced Learner's English Dictionary (New Digital Edition, 2008) it is written: "Competency means the same as competence". Besides, the analysis of a number of works on this subject revealed the usage of both words in an identical collocation:

- $\quad$ competence debate - competency debate $[4,5]$;

- $\quad$ core competence - core competency [6, 7];

- $\quad$ competency-based approach - competence-based approach [8];

- competence movement - competency movement [9].

In summary, we may draw a conclusion that the word competency/competence is used to denote what a person, working in a certain professional area, must be capable to do. In the education system, competency/competence is understood as a result of training a graduate for the performance of an activity in certain professional areas [4-9].

The analysis of publications devoted to competence carried out by Françoise Delamare, revealed that Americans tend to connect competence with basic characteristics of a person, which cause one's outstanding achievements in certain kinds of activity. In Great Britain, there is a prevailing opinion that competence should be defined as compliance of the results of individual's activity with the authorized standards. Continental Europe countries and Russia adhere to a dominating multidimensional concept of competence uniting behavioral and functional concepts [10].

From the classifications of competences, it becomes obvious that researchers in the field of competence-based education allocate key competences also called core competences, basic competences, meta-competences as a separate category of competences. They are considered as competences of a broad scale, not specific to any professional area, and are characterized as universally applied [11-14].

The European Council identified key competences that are fundamental for each individual as a part of one's lifelong learning strategies. The second key competence stipulated by the European Council is a competence in foreign languages that is defined as "communicating in a foreign language: ability to express and interpret concepts, thoughts, feelings, facts and opinions both orally and in writing, also includes mediation skills (i.e. 
summarizing, paraphrasing, interpreting or translating) and intercultural understanding" [15].

According to Russian state higher educational standards students are supposed to acquire key and professional competences specific for their specialty. Foreign language competence is included in the list of key competences for all specialties taught at higher educational institutions.

Relevance of foreign language competence for any specialist aspiring to gain professional success in a career (among them ecology and environment managers) is evident. Lack of foreign language competence of a specialist hinders one's international professional communication and studying cutting-edge achievements in the field of solving professional problems, makes impossible academic mobility and conducting cooperative scientific research with international colleagues.

Consequently, the list of competences specified by state education authorities for postgraduates, who are getting Master's degree in ecology and environment management, includes foreign language competence as an essential means of scientific and professional communication. Knowledge, skills and experience related to foreign language competence for postgraduates, who are getting Master's degree in ecology and environment management, requires: knowledge of vocabulary and functional grammar of scientific texts and documents; skills to understand and produce business, academic or scientific written and spoken messages, to initiate, sustain and conclude conversations concerning the field of scientific research; experience in public speaking with the results of their scientific research.

\section{Results and Discussion}

The aforementioned foreign language competence is acquired through "Foreign Language" discipline. The program of the discipline includes all the aspects of foreign language competence and consists of the following sections: My Master's Course, Characteristic Features of Scientific Discourse, Academic Reading, Academic Writing and Public Speaking. It should also be mentioned that, while creating the program of the discipline, we had to take into account the following facts.

Firstly, the majority of time designated to "Foreign Language" discipline is assumed to be individual students' work (viz. 76 hours out of total 108). In addition, nearly all postgraduates are employed and often have no opportunity to attend classes and tutorials in person. As a result, the main task was to organize individual students' work and to provide them with methodical help and possibility to get private tutorials on-line.

Secondly, the success in mastering foreign language competence by the postgraduates, who are getting Master's degree in Ecology and Environment Management, could be partly hindered by the level of the competence acquired at the previous stage of their education and lack of motivation to get the competence. The reasons of those are the following: (i) according to the state educational standards, at the previous stage of education, leading to Bachelor's degree, foreign language competence is formed during the first two years of studies. So, by the time of postgraduate course students have at least 3-4 years gap in foreign language training; (ii) some postgraduates appear to be qualified specialists in the field of environment management and they are highly estimated by their employers. Sometimes their low level of foreign language competence makes them feel psychological discomfort and causes lack of motivation in acquiring the competence. As a result, we have to persuade students in their ability to master foreign language competence by showing and explaining strategies of individual work, by facilitating their getting through the tasks, by creating assignments they can cope with. 
The authors' long-term practice in foreign language teaching proves that positive motivation helps to overcome lack of foreign language skills. In our opinion, creating positive motivation in students is one of the main duties of any foreign language teacher.

The first section of the discipline, called My Master's Course, contributes to enhancing students' motivation to master foreign language competence. It opens with the text Why Get a Master's Degree? and proceeds with the description of Master's courses in the similar field from the sites of the leading universities in the world. While working on the text, students get the vocabulary necessary to make a presentation My Master's Course. The presentation should include personal educational background, the description of one's Master's course (specialty title, time schedule, disciplines, scientific research area, etc.) along with the information of one's career plans.

The section Characteristic Features of Scientific Discourse is devoted to grammar, vocabulary, stylistic and syntactic peculiarities of academic and scientific discourse in English. While working on this part, postgraduates are referred to scientific journals on Web portals (e.g. https://danieljhocking.wordpress.com/links/oa-journals/) to find an article in English that discusses a topic similar or close to their scientific research.

To acquire and develop experience in understanding scientific discourse, students are to analyze the language of the article (scientific and professional terminology, grammar constructions, etc.), practice their skills in translating and summarizing with the prospect to refer to the article in their Master's paper.

Students are supposed to work individually on the sections of the program Academic Writing and Academic Reading. The purpose of the section Academic Reading is to master postgraduates' skills in different strategies of academic reading: intensive or extensive reading, skimming and scanning. Intensive reading is decoding the message of a text. It deals with the study of grammatical and lexical features. The major objective of extensive reading is developing the ability to extract the necessary information from a text. Skimming is a strategy of previewing an article or a book when it is read quickly with noting only chief points. Scanning is reading for specific information.

Working through the tasks of the section students learn to look for such signals as headlines, introductory and concluding paragraphs, repeated key words and key terms, pictures, names, places and numbers, division into paragraphs, transitional words. Students are taught to see the idea of each paragraph, to find unknown words, terms which can be interpreted by the author of the article. Sometimes students may refer to explanatory or defining dictionaries, encyclopedias. At the same time, there is no need to look for each word in dictionaries as a meaning of some words is deduced from a context. Therefore, it is very important for a teacher to explain the strategy to work with vocabulary of a scientific text.

The requirement to develop skills in academic reading is caused by necessity to work with scientific texts which are notable for their general difficulty of perception, long paragraphs, special vocabulary and complex sentences. The ability to see similar features of a scientific text through its organization becomes a paramount task for a student.

The task of a teacher is to show typical structural features of these texts and to deduce their template character. For example, a scientific article has a uniform structure or a form which is appropriate for texts of any scientific field (introduction, analysis, results, conclusion); books, textbooks or guides are always divided into chapters, sections, etc.

The purpose of the section Academic Writing is to prepare postgraduates to write different kinds of scientific texts in English. For this purpose, postgraduates are to read the text Writing an article and to make a list of recommendations for writing a scientific article; to read the text Writing a Conference Report and to make a list of recommendations for writing a report for a conference; to define a difference between composing a scientific article and composing a report for a conference; to read the text Writing a Thesis and to 
make a list of recommendations for writing a thesis. It should also be noted that the language of the instructions itself serves the aim to master students' foreign language competence.

Special attention is paid to mastering the ability to write an abstract to an article in English since any person, who wants to publish the results of a scientific research in scientific publications, faces this problem. Hence, postgraduates are provided with the examples of articles and corresponding abstracts to carry out their detailed analysis. As a result, students are to prepare an abstract to their own article or some offered articles in English with the use of corresponding speech clichés.

The section Public Speaking contains clues and recommendations how to prepare a presentation, what information is to be included and excluded, how to use demonstration equipment, the speaker's appearance and formulas of business etiquette as well. Students are assumed to study the recommendations and to answer the questions grouped according to the sections of a thesis: Field of Science and Research, Research Problem, Historical Background of Research Problem, Purpose and Methods, Results and Conclusion. On the basis of their answers they make up a presentation My Scientific Research done in compliance with the recommendations offered, and also answer questions of the audience on their research subject.

The presentation My Scientific Research gives the students initial experience of future professional dialogue and interaction with colleagues and partners. It teaches how to select material for discussion proficiently and to state one's own thoughts, how to formulate one's own point of view correctly and to advocate one's personal interests as well as the interests of one's company. Besides, such activity, being correctly organized by a teacher, will remove psychological barriers and typical fears of contact with audience.

Considering that students, who are getting Master's degree in Ecology and Environment Management, have to take their examination on the "Foreign language" discipline at the end of the $3^{\text {rd }}$ semester, they have already conducted certain research and at least intermediate results can be presented by that time. It should be noted that the general scope of all postgraduates' research is connected with the environmental issues of the native region incorporated in the global problems of environment. The research is based both on practical experience, and on extensive theoretical material received at the lectures and seminars. It allows creating harmonious conditions for incorporating the process of mastering foreign language competence in a general course of the Master's educational program. Besides, bilingual vision of the scientific project allows students to understand their research subject more deeply.

\section{Conclusions}

Qualified specialists in ecology and environment management are highly needed for mining industry to solve ecological problems and to prevent ecological disaster that may result from its work. Modern society demands from a specialist to possess competences, and foreign language competence is among the key ones. The content of the "Foreign Language" discipline and the approach to organize students' individual work for Master's course in ecology and environment management contribute to mastering foreign language competence of postgraduates as inherent condition of their professional efficiency and career development. It serves as "a bridge" for establishing foreign contacts, creates conditions for professional experience exchange. The result of the process is the integration of regional coal-mining enterprises of Kuzbass, possessing the staff of such employees, into world industrial community. 


\section{References}

1. J. Habermas, Moralbewusstsein und kommunikatives Handeln (Suhrkamp, Frankfurt am Main, 1983)

2. R.W. White, Psy. Rev., 66 (1959)

3. D.C. McClelland, Amer. Psy., 28, 1-14 (1973)

4. R.B. Brown, Pers. Rev., 22, 25-36 (1993)

5. R.B. Brown, Manag. Learn., 25, 289-299 (1994)

6. A. Snyder, H.W. Ebeling, J. Bus. Strat., 13, 26-32 (1992)

7. H. Scarborough, Brit. J. Manag., 9, 219-232 (1998)

8. J. Burgoyne, Competency Based Approaches to Management Development (Lancaster: Centre for the Study of Management Learning, 1988)

9. I. Bates, Stud. Sci. Educ., 25, 39-68 (1995)

10. F. Delamare Le Deist, Hum. Res. Dev. Int., 8, 27-46 (2005)

11. D. Gibbons-Wood, Education + Training, 42, 24-32 (2000)

12. P. Humphreys, Journal of European Industrial Training, 21, 63-69 (1997)

13. S.C. Schoonover, Implementing Competencies: A Best Practices Approach (London: Schoonover Co, 1998)

14. S. Shaw, Development of Core Skills training in the Partner Countries (ETF, 1998)

15. 15. Official Journal of the European Union. Recommendation of the European Parliament and of the Council of 18 December 2006 on key competences for lifelong learning. URL: http://eur-lex.europa.eu/legal-content/EN/TXT/?uri=celex:32006H0962 